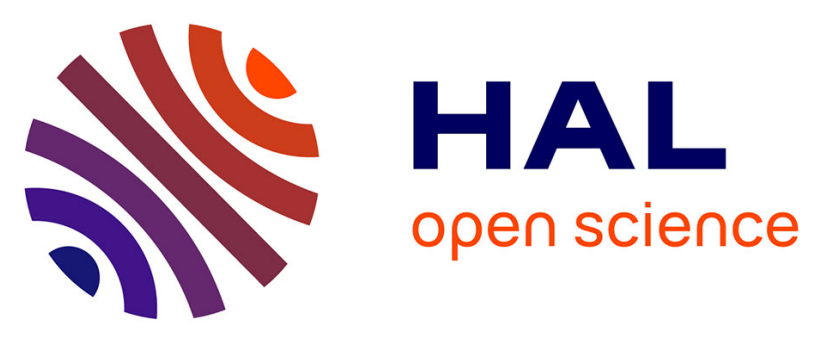

\title{
Spatial distribution of triazine residues in a shallow alluvial aquifer linked to groundwater residence time
}

Lara Sassine, Corinne Le Gal La Salle, Mahmoud Khaska, Patrick Verdoux, Patrick Meffre, Zohra Benfodda, Benoit Roig

\section{- To cite this version:}

Lara Sassine, Corinne Le Gal La Salle, Mahmoud Khaska, Patrick Verdoux, Patrick Meffre, et al.. Spatial distribution of triazine residues in a shallow alluvial aquifer linked to groundwater residence time. Environmental Science and Pollution Research, 2017, 24 (8), pp.6878-6888. 10.1007/s11356016-7224-x . hal-01544262

\section{HAL Id: hal-01544262 \\ https://hal.science/hal-01544262}

Submitted on 11 Jul 2017

HAL is a multi-disciplinary open access archive for the deposit and dissemination of scientific research documents, whether they are published or not. The documents may come from teaching and research institutions in France or abroad, or from public or private research centers.
L'archive ouverte pluridisciplinaire HAL, est destinée au dépôt et à la diffusion de documents scientifiques de niveau recherche, publiés ou non, émanant des établissements d'enseignement et de recherche français ou étrangers, des laboratoires publics ou privés.

\section{(1) (1) $\$$}

Distributed under a Creative Commons Attribution - NonCommercial - NoDerivatives 44.0 


\title{
Spatial distribution of triazine residues in a shallow alluvial aquifer linked to groundwater residence time
}

\author{
Lara Sassine ${ }^{1,2}$ D $\&$ Corinne Le Gal La Salle ${ }^{1}$ \& Mahmoud Khaska ${ }^{1}$ \& Patrick Verdoux ${ }^{1}$ \&
}

Patrick Meffre ${ }^{1} \&$ Zohra Benfodda $^{1}$ \& Benoît Roig ${ }^{1}$

\begin{abstract}
At present, some triazine herbicides occurrence in European groundwater, 13 years after their use ban in the EuropeanUnion,remains of great concern and raises the question of their persistence in groundwater systems due to several factors such as storage and remobilization from soil and unsaturated zone, limited or absence of degradation, sorption in saturated zones, or to continuing illegal applications. In order to address this problem and to determine triazine distribution in the saturated zone, their occurrence is investigated in the light of the aquifer hydrodynamic on the basis of a geochemical approach using groundwater dating tracers $\left({ }^{3} \mathrm{H} /{ }^{3} \mathrm{He}\right)$. In this study, atrazine, simazine, terbuthylazine, deethylatrazine, deisopropylatrazine, and deethylterbuthylazine are measured in 66 samples collected between 2011 and 2013 from 21 sampling points, on the Vistrenque shallow alluvial
\end{abstract}

* Lara Sassine

lara.sassine@unimes.fr

1

Univ. Nîmes, EA 7352 CHROME, rue du Dr Georges Salan, 30021 Nîmes, France

Aix-Marseille Université, CNRS-IRD UM 34 CEREGE, Technopôle de l'Environnement Arbois-Méditerranée, BP80, 13545 Aix-en-Provence, France

Degradation rate aquifer (southern France), covered by a major agricultural land use. The frequencies of quantification range from 100 to $56 \%$ for simazine and atrazine, respectively (LQ $=1 \mathrm{ng}$ $\left.\mathrm{L}^{-1}\right)$. Total triazine concentrations vary between 15 and 350 ng $\mathrm{L}^{-1}$ and show three different patterns with depth below the water table: (1) low concentrations independent of depth but related to water origin, (2) an increase in concentrations with depth in the aquifer related to groundwater residence time and triazine use prior to their ban, and (3) relatively high concentrations at low depths in the saturated zone more likely related to a slow desorption of these compounds from the soil and unsaturated zone. The triazine attenuation rate varies between 0.3 for waters influenced by surface water infiltration and 4.8 for water showing longer residence times in the aquifer, suggesting an increase in these rates with water residence time in the saturated zone. Increasing triazine concentrations with depth is consistent with a significant decrease in the use of these pesticides for the last 10 years on this area and highlights the efficiency of their ban.

Keywords Triazine residues . Persistentorganic pollutants . Shallowalluvial aquifer . Groundwater residence time . Apparent ${ }^{3} \mathrm{H} /{ }^{3}$ Heage . Groundwater origin . Well depth .

\section{Introduction}

Before their prohibition in 2003 in the European Union (EU) due to their endocrine disruptor activities and to their ubiquitous and unpreventable water contamination, atrazine and simazine were highly used as selective herbicides in agricultural crops (e.g. vineyards, orchards, corn) or as total herbicides on railways and roads (Garmouma et al. 2001; Tappe et al. 2002). Despite their prohibition, these compounds are still detected in the environment at Europeanscale,and specifically in groundwater (Lapworth and Gooddy 2006; Loos et al. 2010; Vonberg et al. 2014; Lopez et al. 2015). They remain the most ubiquitous polar pesticides found in aquifers (Köck-Schulmeyer et al. 2014). Although, simazine and atrazine were considered as priority substances in water policies, their occurrence and persistence in aquifers are still of concern. In France, 
atrazine, simazine and terbuthylazine, which was forbidden as well at the French national scale in 2003, along with their degradation compounds, deethylatrazine (DEA), deisopropylatrazine (DIA) and deethylterbuthylazine (DET), were responsible, in 2013, for 2 to $59 \%$ of threshold exceedance of EU drinking water guidelines $\left(0.1 \mu \mathrm{g} \mathrm{L}^{-1}\right.$ per compound except for aldrin, dieldrin and heptachlor) per drinking water distribution unit (General Directorate of Health 2015). The current occurrence of these compounds in the soil (Gevao et al. 2000), the unsaturated zone (Garmouma and Chevreuil 1998) and the saturated zone (Lapworth and Gooddy 2006; Loos et al. 2010; Vonberg et al. 2014; Lopez et al. 2015) of the aquifer highlights their persistence in those environments. According to Tappe et al. (2002), which highlighted the occurrence of atrazine in German aquifers 10 years after its ban, high abundance of these compounds in near-surface groundwater may be due to the wash-out process from the pool of compounds stored in the soil or alternatively to continuing illegal applications. The transport of pesticides from soil to groundwater is affected by different processes including sorption and degradation. It also depends upon additional factors such as the physicochemical properties of the substances (e.g. octanol/water partition coefficient Blog $\mathrm{K}_{\mathrm{OW}},{ }^{\wedge}$ solubility in water $\mathrm{BS}_{\mathrm{W}},{ }^{\wedge}$ vapour pressure, half-life hydrolysis) (Cheng and Koskinen 1986) and the properties and conditions of the soil and the unsaturated zone mainly the organic matter content (Barriuso et al. 1997; Beltran et al. 1998), the clay content, the pH conditions (Celis et al. 1998; Sannino et al. 1999) and the soil moisture (Louchart et al. 2001).

The objective of this study is to evaluate the occurrenceand concentrations of triazine in a shallow alluvial aquifer coupled to the investigation of groundwater residence time. Assuming steady-state flow conditions and a laminar flow system in the saturated zone, one can expect a vertical profile of pesticide concentrations in agreement with the compound input/ recharge function to the system. Hence, groundwater samples are collected at different depths in the aquifer, using existing boreholes, for triazine concentration analyses. Then, groundwater residence time is determined by the tritium-helium $\left({ }^{3} \mathrm{H} /{ }^{3} \mathrm{He}\right)$ method (Schlosser et al. 1988; Schlosser et al. 1989; Cook and Solomon 1997; Suckow 2014) and is defined by the law of radioactive decay. Different tracers can be used for recent groundwater dating as chlorofluorocarbons (CFCs), sulphur hexafluoride $\left(\mathrm{SF}_{6}\right)$, 36-chlorine $\left({ }^{36} \mathrm{Cl}\right)$ and Tritium $\left({ }^{3} \mathrm{H}\right)$ (Dunkle et al. 1993; Alvarado et al. 2005). However, for each tracer, some limitations may cause discrepancies between estimated groundwater age and contamination occurrence. These limitations may be due to contamination or degradation for non-conservative tracers, to low atmospheric variations of the tracer concentrations or, in the case of ${ }^{3} \mathrm{H} /{ }^{3} \mathrm{He}$, to high uncertainty on tritiogenic $\mathrm{He}$ estimation (Darling and Gooddy 2007; McCallum et al. 2015). In this study, the

33

$\mathrm{H} / \mathrm{He}$ method is used as it offers discrete groundwater residence times, while $\mathrm{CFC}$ and $\mathrm{SF}_{6}$ mostly showed contaminations compared to the concentrations at the equilibrium with the atmosphere (Sassine 2014).

At present, only few studies investigated pesticide concentrations in the light of the hydrogeology and hydrodynamic of the aquifer in order to evaluate the occurrence and the fate of these compounds in groundwater (Domagalski and Dubrovsky 1992; Kolpin et al. 1995; Kingsbury 2003; Manning et al. 2005; Lapworth and Gooddy 2006; Baran et al. 2007; Tesoriero et al. 2007; Gourcy et al. 2009). Most of these studies highlighted the importance of the determination of recent recharge fraction in the sample assuming or showing an inverse correlation between contaminants and groundwater residence time. When the contamination occurrence is consistent with groundwater age, groundwater dating proves to be a helpful tool to explain the trend of contaminants in groundwater.

\section{Materials and methods}

\section{Study site}

The study site is a shallow alluvial aquifer, located in southern France, the Vistrenque aquifer, characterized by a medium permeability, varying between $3 \times 10^{-3}$ and $10^{-4} \mathrm{~m}$ $\mathrm{s}^{-1}$. This aquifer is mainly recharged by precipitations and by lateral flow from a karst aquifer located at the northern border. It is locally influenced by surface water infiltration of local stream water or of the Rhône Riverwater imported through a network of channels and used for irrigation, artificial recharge and drinking water supply (Sassine et al. 2015). The general groundwater flow direction is northeast to southwest. As the Vistrenque aquifer is included in a NESW graben structure, lateral flows occur from the northern and the southern borders towards the central part of the catchment.

The major land use on this aquifer is agriculture (Fig. 1). On the basis of the European database of biophysical cover, CORINE Land Cover (2006), the agricultural area is estimated at 26,000 ha which is $80 \%$ of the basin. The agricultural activities include vineyards, which occupy $38 \%$ approximately of the agricultural area, orchards, vegetables and cereals (Fig. 1). This implies frequent applications of 
diverse pesticides, notably of triazine herbicides before their ban in 2003. Due to this intensive agricultural land use and to the thin unsaturated zone of the Vistrenque aquifer, varying between 2 and $7 \mathrm{~m}$, its vulnerability to pesticide contamination is considered high.

On the contrary, the karst area, mainly covered by scrublands, is not affected by any of the triazine
March 2012 and July 2013. In addition, 6 samples were collected from the neighbouring karst aquifer, 30 samples from the Vistre stream and 3 samples from the imported Rhône River canal. In statistical analyses, each sample is considered as an individual item.

Before collecting water samples, agricultural wells were purged with a submersible SDECO pump, with a $5-\mathrm{L} \mathrm{min}^{-1}$
Fig. 1 Map of the study area showing the land cover (Corine Land Cover 2006) and the sampling sites of groundwater and surface water

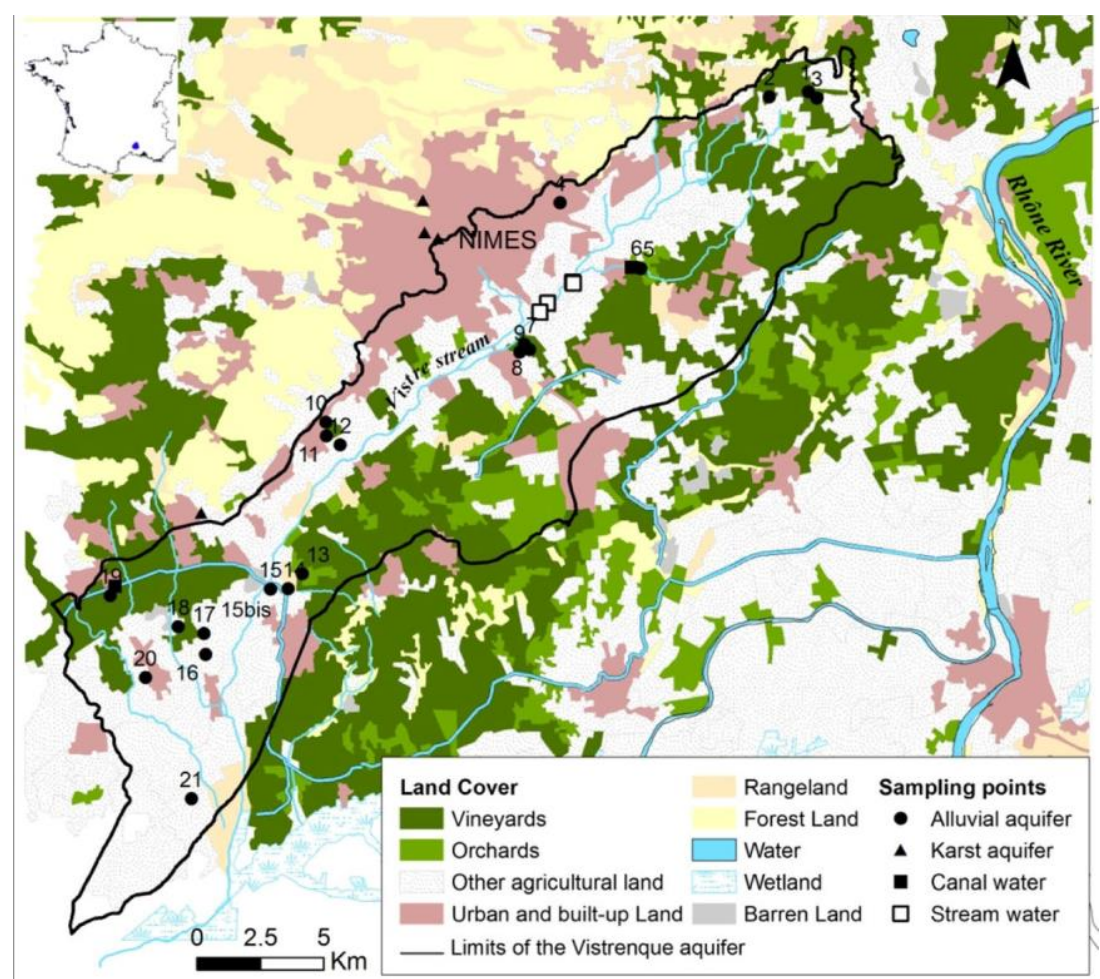

flow, until stabilization of the physicochemical parameters (temperature, $\mathrm{pH}$, oxidoreduction potential, specific conductance at $25{ }^{\circ} \mathrm{C}$ and dissolved oxygen) of groundwater. Wells equipped with pumps were sampled at the tap before any treatment or storage facilities. The physicochemical parameters were measured in situ in a flow-through cell to prevent contact with the atmosphere using a WTW multi 340i.

Analyses of triazine compounds

Water samples for triazine analyses were collected in precleaned and baked, amber glass, 1-L bottles with Teflon lined caps, transported on ice to the laboratory. Samples were filtered through a $0.7-\mu \mathrm{m}$ glass fibre filters (Whatman $\mathrm{GF} / \mathrm{F}$ ) as soon as they were returned to the laboratory and stored at $4{ }^{\circ} \mathrm{C}$ until analyses. Prior to concentration, water was spiked with isotope-labelled internal standards, atrazine- $\mathrm{d}_{5}$ and simazined $_{10}$ (Sigma-Aldrich, France), in order to assess the overall sample analyses recovery area (Fig. 1). Sixty-six samples were collected from the Vistrenque aquifer over 3 sampling campaigns between 
including solid phase extraction, ionization and matrix effects.

Then, water samples $(1 \mathrm{~L})$ were concentrated by solid phase extraction using Oasis HLB (500 mg, $12 \mathrm{~cm}^{3}$ ) cartridges (Waters, Saint-Quentin-en-Yvelines, France) on a vacuum manifold (Phenomenex, Le Pecq, France), and then eluted with $8 \mathrm{ml}$ of methanol $(\mathrm{MeOH})$. The solvent was evaporated under a gentle $\mathrm{N}_{2}$ flow at a temperature of $35^{\circ} \mathrm{C}$ in a sample concentrator (Techne, France), and the dry residues were dissolved in $200 \mu \mathrm{L}$ of $\mathrm{MeOH}$. The extracts were analysed in duplicates by liquid chromatography (Alliance 2695 HPLC, Waters) followed by positive electrospray ionization (ESI) tandem mass spectrometry (Quattro Premier XE, Waters) in the multiple reaction monitoring (MRM) mode.

Analyte separation was achieved using a Waters XBridge C18 column (2.1 mmx100mm, $3.5 \mu \mathrm{m}$ particle size) (SaintQuentin-en-Yvelines, France). The quantification of atrazine, simazine, terbuthylazine, DEA, DIA, and DETconcentrations was performed with Targetlynx software using external calibration. External standards corresponding to the analysed compounds, internal standards (simazine-d10 and atrazined5) and methanol were purchased from Sigma-Aldrich,

France.

Sample concentrations were corrected from recovery rates. Duplicate analyses, run in order to assess the analytical uncertainty, showed a standard deviation less than $10 \%$ for groundwater samples and $13 \%$ for surface water samples. Hence, the analytical uncertainty for the sum of triazine compounds corresponds to the sum of individual uncertainties and is on the order of $60 \%$.

The limits of quantification (LQs) of the method are determined by the analyte concentrations giving a signal-tonoise ratio often corrected from the concentration factorand wereof $1 \mathrm{ng} \mathrm{L}^{-1}$ for one single compound (Table 1). The blank $(\mathrm{MeOH})$ analyses throughout the sample sequences were clear and revealed no memory effect.

The repeatability of the method was estimated using a standard solution of atrazine, simazine, terbuthylazine, DIA, DEA and DET at three different concentrations $\left(20 \mu \mathrm{g} \mathrm{L}^{-1}\right.$ $(n=5), 80 \mu g \mathrm{~L}^{-1}(n=6)$ and $\left.300 \mu \mathrm{g} \mathrm{L}^{-1}(\mathrm{n}=10)\right)$. RSD was calculated as $<30 \%$.

These analyses were carried out at the University of Nîmes.

Determination of groundwater residence time by the ${ }^{3} \mathrm{H} /{ }^{3} \mathrm{He}$ method
The apparent age of groundwater is the time elapsed for water to flow from an area of recharge to an observation point (Suckow 2014). In laminar flow conditions, the age increases along a particular flow path through the groundwater flow system. Groundwater age dating with the ${ }^{3} \mathrm{H} /{ }^{\beta} \mathrm{He}$ method has become a powerful tool for hydrogeologists (Visser et al. 2014).

The ${ }^{3} \mathrm{H} /{ }^{3} \mathrm{He}$ age $\tau$ is defined by the law of radioactive decay as follows (Eq. 1):

$$
\text { - } \quad 1 / 41 \mathrm{p}^{3} \mathrm{He}^{\mathrm{trit}} ! \lambda{ }^{1 / 4} \ln 2 \tau \lambda
$$

$* \ln 13 \mathrm{H}$ with $\mathrm{t} 1=2$

$1 / 40: 05626 a^{-1}$ and $t_{1=2} 1 / 412: 32$ years

where $\lambda$ is the decay constant for ${ }^{3} \mathrm{H} ; \mathrm{t}_{1 / 2}$ is the half-life time for ${ }^{3} \mathrm{H}$ corresponding to 12.32 years; $\left[{ }^{3} \mathrm{He}\right]_{\text {trit }}$ is the concentration of ${ }^{3} \mathrm{He}$ issued from ${ }^{3} \mathrm{H}$ decay, referred as tritiogenic ${ }^{3} \mathrm{He}$ and can be deduced from ${ }^{4} \mathrm{He}$ and ${ }^{20} \mathrm{Ne}$ measurements and $\left[{ }^{3} \mathrm{H}\right]$ is the concentration of ${ }^{3} \mathrm{H}$ measured in the water sample.

Ten sampling sites $(1,3,7,8,9,13,14,15$ bis, 16 , and 18) on the Vistrenque aquifer were selected for the estimation of groundwater age by the ${ }^{3} \mathrm{H} /{ }^{3} \mathrm{He}$ method. Tritium concentrations were determined by ${ }^{3} \mathrm{He}$ ingrowth over a 6-month period (Jean-Baptiste et al. 1992). Analyses of ${ }^{3} \mathrm{H}$ and ${ }^{3} \mathrm{He}$ isotopes were carried out at the LSCE, CEA/Saclay (Gif-sur-Yvette, France) with a MAP-215 mass spectrometer using standard procedures. Samples for ${ }^{3} \mathrm{H}$ analyses were collected in 500-mL pre-degassed glass bottles and pre-filled with nitrogen gas. Samples for ${ }^{3} \mathrm{He}$, ${ }^{4} \mathrm{He}$ and ${ }^{20} \mathrm{Ne}$ analyses were collected using clamped copper tubes ( $20 \mathrm{~cm}$ long section with $3 / 8$ in of diameter), rinsed thoroughly before sampling to avoid air bubbles. Noble gas samples were collected in duplicates showing good agreement for all samples. The analytical method is detailed in Jean-Baptiste et al. (2010, 1992).

Uncertainties on apparent ${ }^{3} \mathrm{H} /{ }^{3} \mathrm{He}$ age, depending on the analytical precision of the ${ }^{3} \mathrm{H}$ measurement and on the uncertainty of the tritiogenic ${ }^{3} \mathrm{He}$ component estimation, are calculated as given in Visser et al. (2014).

Results and discussion

Variation of triazine concentrations with land use and groundwater origin 
Considering the method LQ $\left(1 \mathrm{ng} \mathrm{L}^{-1}\right)$, simazine, DIA, DEA and DETshow $100 \%$ quantification in the Vistrenque alluvial groundwater samples $(n=66)$, while atrazine and terbuthylazine are respectively quantified in 56 and $59 \%$ of the samples (Table 1; Fig. 2). Simazine was highly used on the Vistrenque area, on vineyards and orchards, due to its low cost and high efficiency, while atrazine was mainly used on corn culture. These quantification frequencies are more likely related to the different land use proportions but can also depend on the compound half-life and its mobility in the hydrosystem.

In the Vistrenque groundwater, the average concentrations per compound are on the order of 10 to $20 \mathrm{ng}$ $\mathrm{L}^{-1}$ (Table 1). Among parent compounds, atrazine shows the wider concen-

trationsrange varying between $<\mathrm{LQ}$ and $109 \mathrm{ngL}$. The most significant concentrations ( 35 to $110 \mathrm{ng} \mathrm{L}^{-1}$ ) were observed on the southern area of the aquifer, previously occupied by corn culture during the past 10 years, at sites 19, 20, and 21 . On the remaining sampling points, atrazine concentrations are on the order of few nanograms per litre only, when it was detected. Simazine and terbuthylazine showed smaller variations ranging from $<\mathrm{LQ}$ to 40 and $30 \mathrm{ng} \mathrm{L}^{-1}$, respectively (Table 1).

Overall, degradation compounds showed higher concentrations than did parent compounds in the Vistrenque aquifer. DEA exhibits a large range of concentrations varying between 1 and $142 \mathrm{ng} \mathrm{L}^{-1}$, DIA reaches $107 \mathrm{ng} \mathrm{L}^{-1}$ and finally DET reaches $70 \mathrm{ng} \mathrm{L}^{-1}$ (Table 1).

Sampling points showing low concentrations, on the order of the method LQ, exhibit high relative standard deviation (RSD) reaching $55 \%$, over the different sampling campaigns, while those showing higher concentrations show no significant variations over time during this study, except for site 1 (Table 1 in Supplementary material).

Karst groundwater samples $(n=6)$, stream water $(n=30)$ and imported Rhône River water $(n=3)$ showed lower frequencies of quantification of triazine compounds and lower concentrations than those of the alluvial groundwater, with average concentrations per compound not exceeding 10 ng $\mathrm{L}^{-1}$, in accordance with Sassine et al. (2015). For karst groundwater, these results may be explained by the land cover over the karst area, mainly occupied by scrublands or lightly urbanized, not requiring any treatment with selective herbicides of agricultural uses (Sassine et al. 2015) (Fig. 1). In surface water, the very low concentrations of triazine compounds are most likely due to their ban, and therefore, to the cessation of their input pattern in streams by surface runoff over agricultural field. Therefore, a significant 
contribution from these water bodies to the recharge of the Vistrenque aquifer induces a dilution of triazine concentrations.

According to the range of individual concentrations, the sampling sites in this study are classified in two groups. The first one (group I) shows low concentrations ranging from a few ng L $\mathrm{L}^{-1}$ to $20 \mathrm{ng} \mathrm{L}^{-1}$ that are likely due (i) to a dilution of triazine content either with an important lateral karst recharge (sites 2, 4, 10, 11, and 12) or with the infiltration of surface water (sites 5, 6, 15 and 15bis) (Sassine et al. 2015) (group Ia) and (ii)to low triazineuseson landcrop for sites influenced by direct recharge or by important attenuation processes (Group Ib including sites 7, 8 and 9) (Fig. 2).

The second group (group II) shows higher triazine

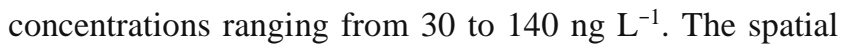
concentration distribution most likely depends on previous triazine input pattern and transfer to groundwater by direct recharge or on the remobilization of these compounds from

Fig. 2 Spatial repartition of triazine concentrations in groundwater and surface water (circled with a dotted line) at sampling sites on the

Vistrenque area during the August 2012 campaign, drawn on a geological background influenced by the recharge origin of groundwater (group Ia). The triazine concentrations should be discussed with respect to the depth of the well below the water table in order to examine their vertical spatial distribution especially for sites of Group II.

Variation of triazine concentrations with groundwater depth

Globally, inverse relations between well depths and pesticide detection frequencies or concentrations have been documented (Barbash and Resek 1996), as shallower wells are generally considered more prone to anthropogenic contamination than deeper wells are (Burow et al. 1998). However, in response to reductions in chemical applications to crop land due to their use ban, recent recharge water should be less contaminated than previous recharge. Hence, the quality of shallow groundwater should improve before the quality of deep groundwater due to dilution and diffusion processes (Castaneda and Bhuiyan 1996). In order to the soil and the unsaturated zone, without the influence of additional recharge processes. A continuous illegal use may represent an alternative explanation when parent compound show high concentrations. This group includes sites at shallow depths in the aquifer (group IIa: sites 1, 13, 17, 18, 19 and 21) and others at deeper ones (Group IIb: sites 3, 14, 16 and 20) (Fig. 2). Over these sampling points, site 21 shows the highest triazine concentrations exceeding the drinking water threshold of $100 \mathrm{ng} \mathrm{L}^{-1}$. This site is located at the outflow area of the aquifer where the latter is confined with Quaternary fluvial silt deposits (Fig. 2). This layer is characterized by lower permeability than the Vistrenque sediments and may have prevented triazine dilution, by limiting local recharge infiltration.

Thus, the occurrence of triazine compounds in the Vistrenque aquifer is not only influenced by previous triazine application patterns on land surface but is also strongly

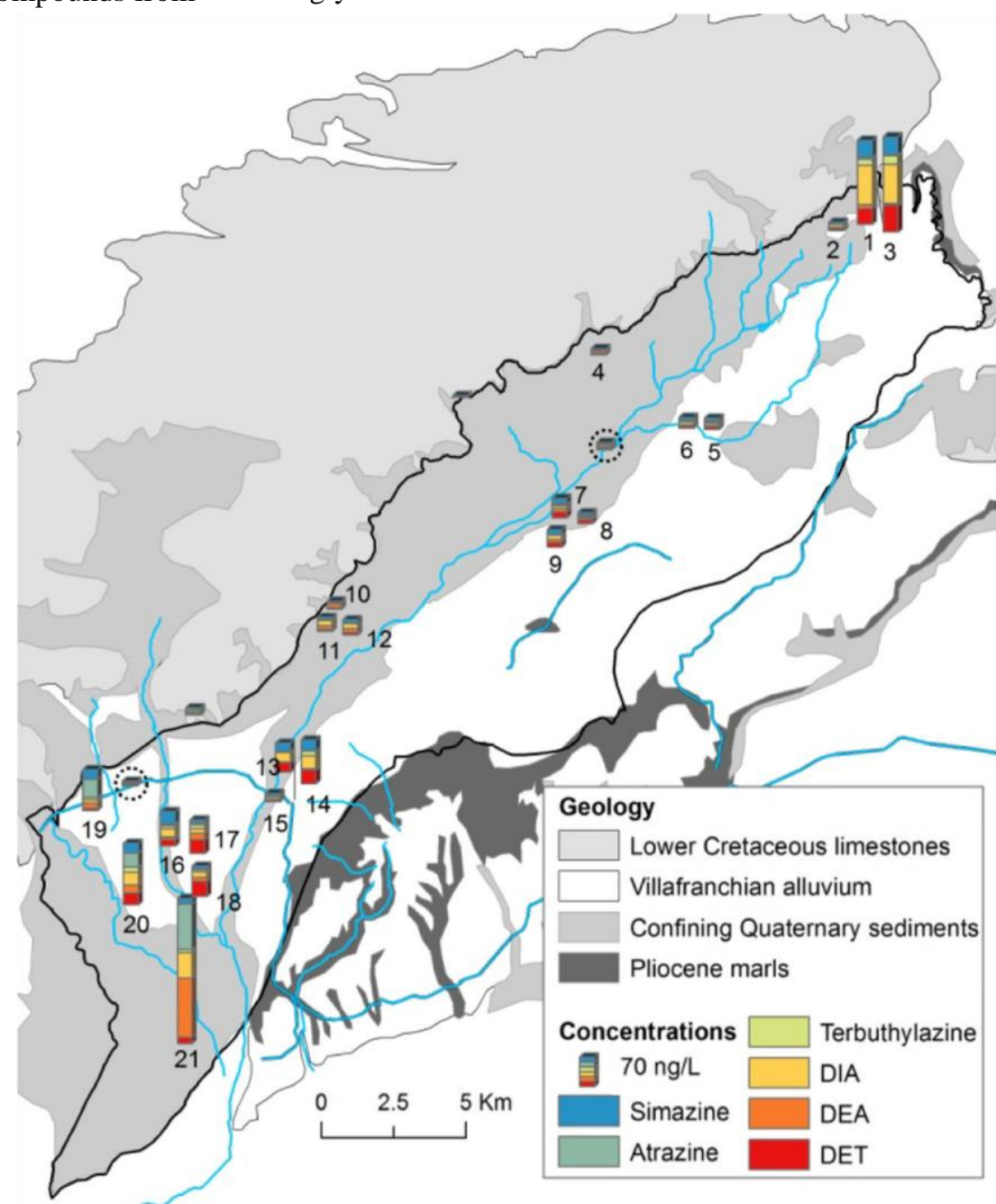

determine the distribution of triazine concentrations in the depth of the saturated zone of the Vistrenque aquifer, the total triazine average concentrations were calculated at each 
sampling point over the sampling campaigns (Table 1 in Supplementary Material). These total triazine average concentrations are represented versus the depth of groundwater below the water table (Fig. 3). The sample depth was taken at the bottom of the well screen. Three main trends are observed:

Trend I shows low triazine concentrations at all depths in the alluvial aquifer. This affects sampling sites located at the northern border of the aquifer and is mainly due to triazine dilution in the Vistrenque aquifer occasioned by stream water infiltration or lateral recharge, as discussed above (group Ia).

TrendII shows increasingconcentrationswithgroundwater depth in the saturated zone (Groups Ib and IIb). This may be related to triazine dilution in the upper level of the aquifer with recent direct recharge. It highlights the transport of triazine parent compounds and degradates with groundwater flows in the depth of the aquifer and their persistence in the deepest level of the saturated zone of the aquifer (group IIb). These residual concentrations are related to triazine applications on land surface prior to their ban.

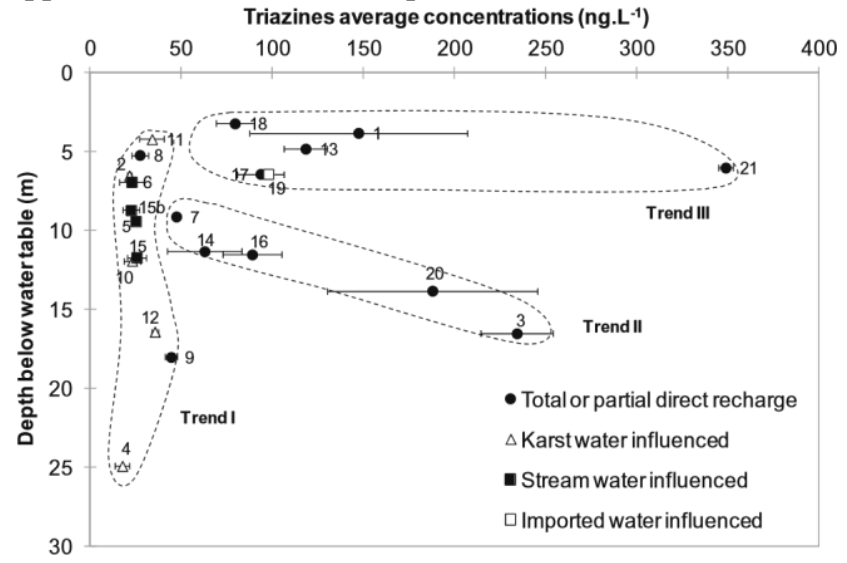

Fig. 3 Variations of triazine average concentrations with groundwater depth in the Vistrenque aquifer showing three different trends. The horizontal error bars represent the standard deviation on the calculated average concentrations on different sampling campaigns

Trend III shows relatively high triazine concentrations in the near-surface groundwater, between 3- and 7-m depths below the water table (group IIa). These relatively high pesticide contents could result from (i) a slow wash-out or remobilization of triazine residues persisting in the unsaturated zone and in the soil due to its composition and more precisely its organic matter content (Barriuso et al. 1997; Beltran et al. 1998), clay content, pH conditions (Celis et al. 1998; Sannino et al. 1999) and soil moisture (Louchart et al. 2001) as shown by the sorption-desorption experiments or (ii) potentially to recent illegal uses of these herbicides.
However, the evolution of triazine concentrations in time on the same sampling point may bring some insight as to which of these two hypotheses is more likely. Triazine compounds had been analysed at sites 19 and 20 between 2000 and 2002, before their usage prohibition, within the framework of groundwater quality assessment by the township joint venture of the Vistrenque and the Costières groundwaters (SMNVC 2002). As shown in Table 2, atrazine, simazine

Table 2 Comparison of triazine analyses $\left(\mathrm{ng} \mathrm{L}^{-1}\right)$ on sampling sites 19 and 20 between 2001 and 2012

\begin{tabular}{|c|c|c|c|c|}
\hline \multirow[t]{2}{*}{ Compounds } & \multirow{2}{*}{$\begin{array}{l}\text { Site } 19 \\
2001^{\mathrm{a}}\end{array}$} & \multirow[b]{2}{*}{2012} & \multicolumn{2}{|l|}{ Site 20} \\
\hline & & & $2001^{\mathrm{a}}$ & 2012 \\
\hline Atrazine & 90 & 25 & 180 & 30 \\
\hline Simazine & 100 & 45 & 100 & 60 \\
\hline Terbuthylazine & 30 & 5 & 70 & 20 \\
\hline DIA & nd & 10 & 120 & 50 \\
\hline DEA & 20 & 15 & 60 & 30 \\
\hline DET & nd & 5 & 90 & 40 \\
\hline
\end{tabular}

nd not detected

a

SMNVC (2002)

and terbuthylazine concentrations measured at sites 19 and 20 in 2012 are lower by two to six times than those reported at the same sampling sites 11 years ago. Unfortunately, monitoring data lacks between 2001 and 2012. However, decreasing concentrations overtime do not support the hypothesis of an illegal use of pesticides. Moreover, illegal use of pesticides would lead to an increase in parent compound concentrations in near-surface groundwater with respect to degradation compounds, which is not the case observed in trend III.

Variation of triazine concentrations with groundwater residence time

The relation between groundwater residence time and triazine concentrations is evaluated using ${ }^{3} \mathrm{H} /{ }^{3} \mathrm{He}$ analyses. The concentrations of ${ }^{3} \mathrm{H}$ and ${ }^{3} \mathrm{He}_{\text {trit }}$ show a wide range, varying between 8.4 and $29 \mathrm{TU}$ for ${ }^{3} \mathrm{H}$ and between 1.6 and $24.8 \mathrm{TU}$ for

${ }^{3} \mathrm{He}_{\text {trit. }}$ Using Eq. 1, the apparent $\mathrm{H} / 3$ He age of groundwater varied between 1.4 and 21.9 years for a recharge temperature of $15{ }^{\circ} \mathrm{C}$ (Sassine 2014). Considering a steady-state flow with direct recharge in the Vistrenque alluvial aquifer, the 
groundwater residence time should increase from the shallower levels of the saturated zone to the deepest ones with subhorizontal isochrones. In this study, groundwater apparent age is globally consistent with groundwater depth in the saturated area of the aquifer (Sassine 2014). Some sites make exception as site 18, slightly influenced by karst water recharge and showing relatively old apparent ${ }^{3} \mathrm{H} /{ }^{3} \mathrm{He}$ age with respect to its shallow depth; and sites 9 and 15 bis, corresponding to municipal wells and showing young apparent ${ }^{3} \mathrm{H} /{ }^{3} \mathrm{He}$ age with respect to their depth that may be explained by the presence of a high fraction of recent groundwater (Sassine 2014), as screens of municipal wells are often installed at considerable depths (10 to $15 \mathrm{~m}$ ) below the water table.

Over the ten groundwater samples analysed for ${ }^{3} \mathrm{H} /{ }^{3} \mathrm{He}$ and triazine concentrations, seven samples show apparent ${ }^{3} \mathrm{H} /{ }^{3} \mathrm{He}$ age younger than 2003 (sites $1,7,8,9,13,14,15$ bis), varying between 1 and 6 years.Mostofthese samples display low total triazine concentrations varying between 25

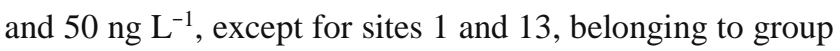
III and displaying higher concentrations of 166 and $123 \mathrm{ng}$ $\mathrm{L}^{-1}$ respectively. As discussed above, these high concentrations may be related to the remobilization of triazine from the soil and unsaturated zone depending on their properties such as to organic matter, clay contents, $\mathrm{pH}$ conditions and soil moisture.

The remaining three groundwater samples show apparent 33

$\mathrm{H} / \mathrm{He}$ age older than 2003 ( sites 3, 16, 18), varying between 14 and 22 years, and display relatively higher total triazine concentrations varying between 81 and $229 \mathrm{ng} \mathrm{L}^{-1}$. 
Hence, over the ten samples analysed for ${ }^{3} \mathrm{H}$ and ${ }^{3} \mathrm{He}$, excluding sites 1 and 13, some molecules such as terbuthylazine, simazine and DETconcentrations would of groundwater residence time and triazine concentrations. Considering sites 1 and 3, located in the same cluster and showing contrasting groundwater ages (3 and 14.5 years
Fig. 4 Variation of triazine individual concentrations with apparent ${ }^{3} \mathrm{H} /{ }^{3} \mathrm{He}$ age of groundwater for the July 2013 sampling campaign. Horizontal error bars correspond to estimated uncertainties on groundwater age according to Visser et al. (2014). Vertical error bars represent the standard deviations on duplicate analyses
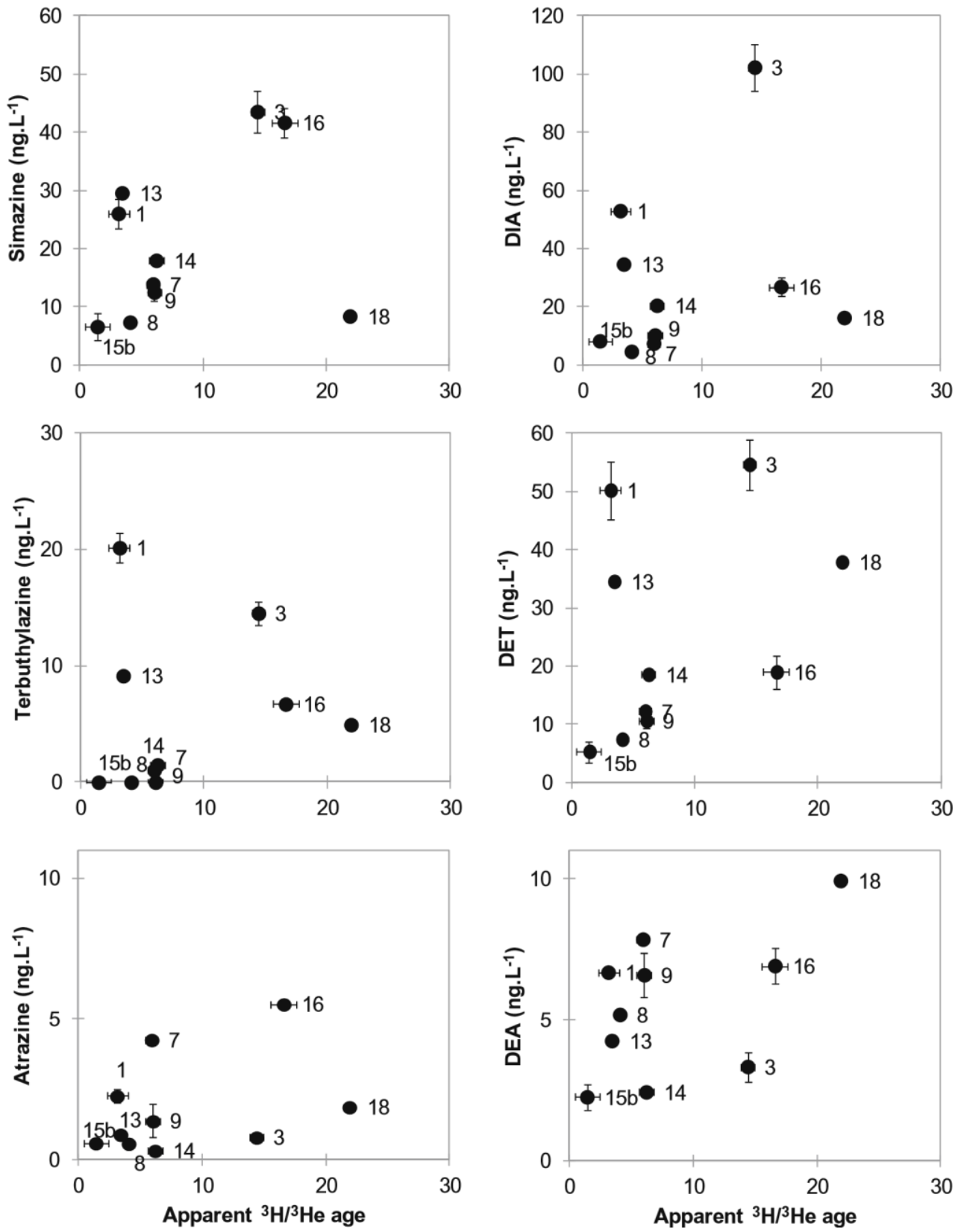

tend to increase with increasing groundwater residence time (Fig. 4). This trend between the parent compound concentrations and groundwater apparent ${ }^{3} \mathrm{H} /{ }^{3} \mathrm{He}$ age supports the conclusion that parent compound contents are lower in recently recharged groundwater than in Bolder^ groundwater. However, it should be confirmed with further groundwater residence time analyses. This conclusion is consistent with reductions in simazine and terbuthylazine application to the land surface.

At first glance, the dilution rate of triazine content in the saturated zone of the aquifer can be estimated on the basis respectively) and different triazine concentrations, a global triazine attenuation rate is estimated at $8 \mathrm{ng} \mathrm{L}^{-1}$ year ${ }^{-1}$. On the other hand, on the basis of the data presented in Table 2, the global triazine attenuation rate varies between 12 and 35 ng L- ${ }^{1}$ year $^{-1}$. These observations should be supported by further groundwater age determinations.

In general, the transport and the dissipation processes of contaminants in aquifers depend on chemical reactions, compound properties and on the aquifer properties. In a first approach and ignoring transformation and sorption processes, the time lag between triazine ban and their 
dissipation from the saturated zone depends mainly on hydrodynamic dispersion governed by soil and aquifer characteristics including sediment hydraulic conductivity, recharge rate of the aquifer and groundwater flow patterns.

Fig. 5 a Comparison of triazine degradate concentrations to parent compound concentrations $(n=66)$; b representation of triazine degradation ratio (TDR) with the depth of groundwater in the saturated zone $(n=66)$; $\mathrm{c}$ representation of TDR with apparent ${ }^{3} \mathrm{H} /{ }^{3} \mathrm{He}$ age $(n=10)$

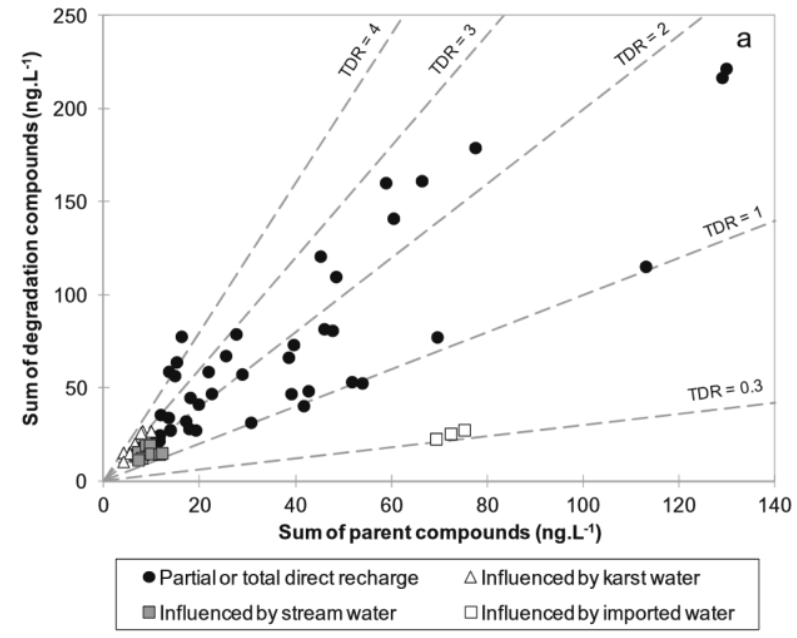

Low ratios would show that only minimal degradation
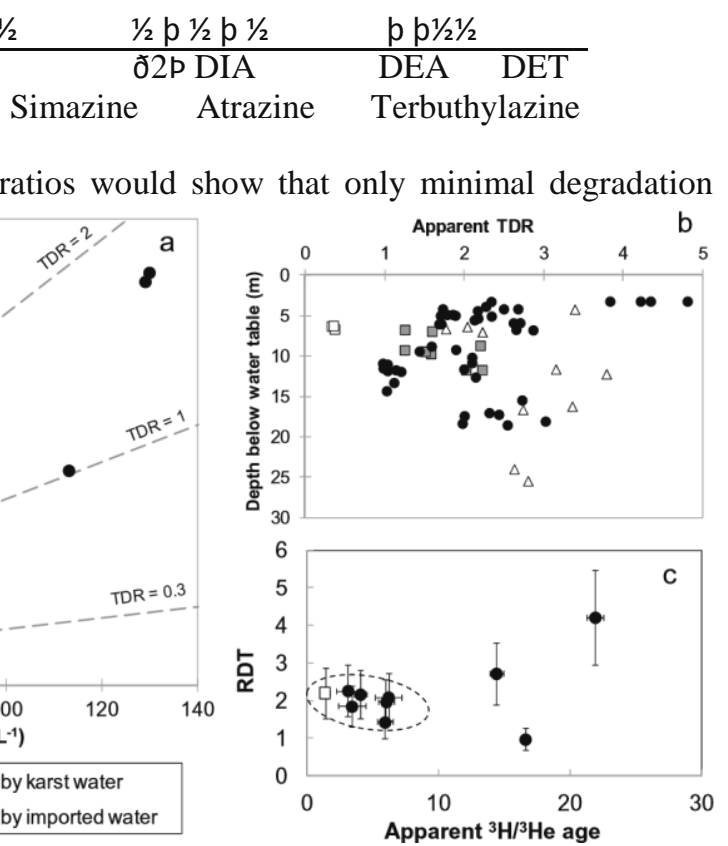

Thus, the Vistrenque aquifer, characterized by a medium permeability varying between 8 and $260 \mathrm{~m} \mathrm{day}^{-1}$, may take decades to hundred years to be flushed, based on a simple Darcy's Law approach.

However, transport and dissipation processes must be completed by degradation rates in order to better investigate triazine attenuation and fate in the hydrogeosystem.

Apparent triazine degradation rates in the Vistrenque hydrogeosystem

As seen before, triazine degradates were found more frequently and at higher concentrations than their parent compounds in most of the samples analysed for this study, indicating also the persistence of degradates in the hydrogeosystem. Although, most triazine parent compounds can be biodegraded in soils and in the unsaturated zone (Mills and Thurman 1994; Rodríguez and Harkin 1997; Blume et al. 2004), where most microbial activity takes place, further degradation may occur in the saturated zone of the aquifer (Steele et al. 2008; Stackelberg et al. 2012). According to previous studies (McMahon et al. 1992; Kolpin et al. 1997; Steele et al. 2008), as the parent compounds were detected in both shallow and deep wells in the aquifer, degradation rates of triazine parent compounds are slowerthantheir transport rates through advection in groundwater.

In order to investigate the apparent degradation rates of triazine parent compounds, the degradation product concentration to parent compound concentration ratios are used. Hence, apparent triazine degradation ratios (TDRs) will be calculated as follows (Eq. 2): had occurred, both in top soil and groundwater, promoting the persistence of parent compounds in the hydrologic system.

High ratios would show that parent compounds had been subject to degradation, either in the aquifer or prior to being transported to the aquifer (Pedersen 2000).

In the Vistrenque alluvial aquifer, triazine degradation compound concentrationsmainly exceededthose of the parent compounds, resulting in a mean TDR of 2.1. TDR varied between 0.3 and 4.8 for the 66 alluvial groundwater samples (Fig. 5a), showing variable but significant degradation of the parent molecule. Groundwater origin show no significant influence on TDR as dilution would occur for parent compounds and degradation products. However, groundwater at site 19 arises as an outlier. Influenced by imported water and located at $300 \mathrm{~m}$ downgradient from the irrigation canal, site 19 exhibits the lowest TDR of 0.3 over the different sampling campaigns (Fig. 5a). The low degradation rate suggests that parent compounds were mobilized and transported from the sourceand through the unsaturated zonebyrapid by-pass flow to the saturated zone. This hypothesis implies a low interaction of the herbicides with the sediments and a rapid infiltration of water in the saturated zone, not allowing much degradation of residual triazine compounds. Although the groundwater level varied during the different sampling campaigns, the TDR remained low suggesting a permanent source of triazine.

The highest TDR of 4.8 is observed at site 16 , where groundwater is characterized by long residence time. This high TDR may be related to both the groundwater residence time coupled to degradation processes in the saturated zone 
of the aquifer and to triazine degradation in the unsaturated zone.

Yet, there is no clear trend between TDR and the sample depthbelowthewatertableduetothewiderangeofTDRvalues already present at shallow depths and probably linked to degradation processes in the soil and the unsaturated zone (Fig. 5b).

As discussed above, depth of groundwater can give estimation of its residence time in the aquifer, but this approach is further refined with the age of groundwater. When comparing the TDR to the apparent ${ }^{3} \mathrm{H} /{ }^{3} \mathrm{He}$ ages of groundwater for the ten analysed samples (Fig. 5c), it is noted that for the recently recharged groundwater (apparent age $<6$ years), TDR varies between 1.4 and 2.2, suggesting some decrease in parent compound concentrations in the recently infiltrating water. While for Bolder groundwater^, TDR varies between 1 and 4.2, confirming the hypothesis of increasing TDR below the water table. However, the apparent TDR is only used to estimate a global degradation process on the aquifer scale, unlike molecular ratios between parent compounds and their metabolites, which are used to characterize the transfer time in the hydrogeosystem. Different limitations may influence the use of TDR in transfer time characterization as the transformation of the degradation compounds, producing second-generation degradates as deethyldeisopropyl atrazine, or the variable amounts of parent compounds used over the surface depending on the land use, or the production of common metabolites.

\section{Conclusion}

Simazine in addition to triazine degradates were the most relevant compounds in the Vistrenque shallow alluvial aquifer but were quantified globally at low concentrations,

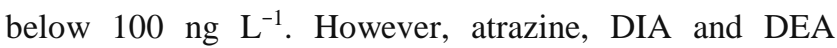
exceeding drinking water threshold were detected punctually. Triazine concentrations tend to increase with groundwater residence time in the aquifer, in coherence with a significant decrease in the use of these compounds since 10 years due to their ban, highlighting an improvement of groundwater quality towards these compounds by dilution with recharge. However, their persistence in saturated zones due to the low or limited degradation process remains an issue, especially for water bodies used for drinking water supply.

The spatial distribution and temporal evolution of triazine contamination in the Vistrenque groundwater depend on (i) groundwater origin as influence from the adjacent karst aquifer and from surface water induces a dilution of triazine contamination, (ii) the hydrodynamic of the aquifer such as groundwater residence time and recharge rate as older groundwater showed higher concentrations than that as a younger one, (iii) the applied rate of parent molecules. It would be interesting to compare these results to compounds of actual use.

On the unconfined area of the Vistrenque aquifer, the dilution rate, influenced by the recharge rate of the aquifer, varied between 8 and $35 \mathrm{ng} \mathrm{L}^{-1}$ year $^{-1}$ for the sum of the analysed triazine compounds on three different sites. The soil and unsaturated zone properties may also play an important role on the storage of triazine and their remobilization to the saturated zone and should be characterized on wells of group IIa.

The vertical profiles of triazine concentrations in the depth of the aquifer are contrasting with the one observed in previous studies where recent groundwater showed higher contamination levels than the deepest one did.

Considering the hydrodynamic aspect of the aquifer is a crucial tool in water pollution assessment to study the evolutionary trends of pollutant concentrations in groundwater bodies when temporal monitoring data are not sufficient or are lacking. Especially that, in the field of European water policy, these trends should be explained by State Members in case of non-achievement of good status recommended by the European Water Framework Directive (WFD-2000/60/EC, OJEC2000).

Acknowledgments The PhD grant of L. Sassine was supported by the General Council of the Gard Department, the Urban Agglomeration of Nîmes Metropole, the University of Nîmes, and by the Joint Venture of the Vistrenque and the Costières Groundwaters. This work has been partially financedthrough the project funded byONEMA, in the frame of the collaborative international consortium WATERJPI2013PERSIST of the Water Challenges for a Changing World Joint Programming Initiative (Water JPI) Pilot Call.

The landowners and the stakeholders are gratefully thanked for giving us the access to the boreholes. The authors also wish to thank Marine Brogat and Amélie Sellier for their technical help in LC/MSMS analyses.

\section{References}

Alvarado JAC, Purtschert R, Hinsby K, et al. (2005) $36 \mathrm{Cl}$ in modern groundwater dated by a multi-tracer approach $(3 \mathrm{H} / 3 \mathrm{He}, \mathrm{SF} 6$, CFC-12 and $85 \mathrm{Kr}$ ): a case study in quaternary sand aquifers in the Odense pilot River Basin, Denmark. Appl Geochem 20:599-609. doi:10.1016/j.apgeochem.2004.09.018

Baran N, Mouvet C, Négrel P (2007) Hydrodynamic and geochemical constraints on pesticide concentrations in the groundwater of an 
agricultural catchment (Brévilles, France). Environ Pollut 148: 729-738. doi:10.1016/j.envpol.2007.01.033

Barbash J, Resek E (1996) Influence of pesticides properties, environmental setting, and study design on pesticide detections. In: pesticides in groundwater: distribution, trends, and governing factors. Ann Arbor Press, Inc.; CRC Press, Chelsea, MI; Boca Raton, FL, p. 590

Barriuso E, Houot S, Serra-Wittling C (1997) Influence of compost addition to soil on the behaviour of herbicides. Pestic Sci 49:6575. doi:10.1002/(SICI)1096-9063(199701)49:1<65::AIDPS488>3.0. CO;2-Z

Beltran J, Gerritse RG, Hernandez F (1998) Effect of flow rate on the adsorption and desorption of glyphosate, simazine and atrazine in columns of sandy soils. Eur J Soil Sci 49:149-156. doi:10.1046/j.1365-2389.1998.00132.x

Blume E, Bischoff M, Moorman TB, Turco RF (2004) Degradation and binding of atrazine in surface and subsurface soils. J Agric Food Chem 52:7382-7388. doi:10.1021/jf049830c

Burow K, Stork S, Bubrovsky N (1998) Nitrate and pesticides in ground water in the eastern San Joaquin Valley, California: occurrence and trends. USGS report. 33p

Castaneda AR, Bhuiyan SI (1996) Groundwater contamination by rice field pesticides and some influencing factors. J Environ Sci Heal Part A Environ Sci Eng Toxicol 31:83-99. doi:10.1080 /10934529609376345

Celis R, Cornejo J, Hermosin M, Koskinen W (1998) Sorption of atrazine and simazinebymodel associations of soil collides. Soil Sci SocAm J 62:165-171

Cheng H, Koskinen WC (1986) Processes and factors affecting transport of pesticides to ground water. In: Evaluation of pesticides in ground

water. $573 \mathrm{p}, \mathrm{p} 2-13$

Cook PG, Solomon DK (1997) Recent advances in dating young groundwater: chlorofluorocarbons, $3 \mathrm{H} / 3 \mathrm{He}$ and $85 \mathrm{Kr}$. J Hydrol 191:245-265

Darling WG, Gooddy DC (2007) Assessing the applicability of global $\mathrm{CFC}$ and $\mathrm{SF}(6)$ input functions to groundwater dating in the UK. Sci Total Environ 387:353-362. doi:10.1016/j.scitotenv.2007.06.015

Domagalski JL, Dubrovsky NM (1992) Pesticide residues in ground water of the San Joaquin Valley, California. J Hydrol 130:299338. doi:10.1016/0022-1694(92)90115-C

Dunkle S, Plummer L, Busenberg E, et al. (1993) Chlorofluorocarbons $(\mathrm{CCl} 3 \mathrm{~F}$ and $\mathrm{CCl} 2 \mathrm{~F} 2)$ as dating tools and hydrologic tracers in shallow groundwater of the Delmarva peninsula, Atlantic coastal plain, United States. Water Resour Res 29:3837-3860

Garmouma M, Blanchoud H, Teil M, et al. (2001) Triazines in the Marne and the Seine rivers (France): longitudinal evolution and flows. Water Air Soil Pollut 132:1-17

Garmouma M, Chevreuil M (1998) Triazine dispersion and distribution in the unsaturated zone of drained soils in the brie (France). Water Air Soil Pollut 108:129-148

General Directorate of Health (2015) Bilan de la qualité de l'eau au robinet du consommateur vis-à-vis des pesticides en 2013. Ministère des affaires sociales, de la santé etd es droits de la femme. 14p. (In French)

Gevao B, Semple KT, Jones KC (2000) Bound pesticide residues in soils: a review. Environ Pollut 108:3-14

Gourcy L, Baran N, Vittecoq B (2009) Improving the knowledge of pesticide and nitrate transfer processes using age-dating tools $(\mathrm{CFC}, \mathrm{SF} 6,3 \mathrm{H})$ in a volcanic island (Martinique, French West
Indies). J Contam Hydrol 108:107-117. doi:10.1016/j.jconhyd.2009.06.004

Jean-Baptiste P, Fourré E, Dapoigny A, et al. (2010) (3)He mass spectrometry for very low-level measurement of organic tritium in environmental samples. J Environ Radioact 101:185-190. doi:10.1016 /j.jenvrad.2009.10.005

Jean-Baptiste P, Mantisi F, Dapoigny A, Stievenard M (1992) Design and performance of a mass spectrometric facility for measuring helium isotopes in natural waters and for low-level tritium determination by the $3 \mathrm{He}$ ingrowth method. Int $\mathrm{J}$ Rad Appl Instrum A 43:881-891

Kingsbury, JA (2003) Shallow ground-water quality in agricultural areas of Northern Alabama and Middle Tennessee, 2000-2001. USGS report. $45 p$

Köck-Schulmeyer M, Ginebreda A, Postigo C, et al. (2014) Four-year advanced monitoring program of polar pesticides in groundwater of Catalonia (NE-Spain). Sci Total Environ 470-471:1087-1098. doi:10.1016/j.scitotenv.2013.10.079

Kolpin DW, Goolsby DA, ThurmanEM (1995) Pesticides in nearsurface aquifers - an assessment using highly sensitive analytical methods and tritium. J Environ Qual 24:1125-1132. doi:10.2134 /jeq1995.00472425002400060011x

Kolpin DW, Kalkhoff SJ, Goolsby DA, et al. (1997) Occurrence of selected herbicides and herbicide degradation products in Iowa's groundwater, 1995. Ground Water 35:679-688

Lange J (2010) Bilan de la qualité de l'eau des nappes Vistrenque et Costières. Au regard des nitrates et des pesticides. Master dissertation, University of Montpellier 2. 43 P. (In French)

Lapworth DJ, Gooddy DC (2006) Source and persistence of pesticides in a semi-confined chalk aquifer of Southeast England. Environ Pollut

144:1031-1044. doi:10.1016/j.envpol.2005.12.055

Loos R, Locoro G, Comero S, et al. (2010) Pan-European survey on the occurrence of selected polar organic persistent pollutants in ground water. Water Res 44:4115-4126. doi:10.1016/j.watres.2010.05.032 Lopez B, Ollivier P, Togola A, et al. (2015) Screening of French groundwater for regulated and emerging contaminants. Sci Total Environ 518-519:562573. doi:10.1016/j.scitotenv.2015.01.110

Louchart X, Voltz M, Andrieux P, Moussa R (2001) Herbicide transport to surface waters at field and watershed scales in a Mediterranean vineyard area. J Environ Qual 30:982-991. doi: 10.2134 /jeq2001.303982x

Manning AH, Kip Solomon D, Thiros SA (2005) $3 \mathrm{H} / 3 \mathrm{He}$ age data in assessing the susceptibility of wells to contamination. Ground Water 43:353-367. doi:10.1111/j.1745-6584.2005.0028.x

McCallum JL, Cook PG, Simmons CT (2015) Limitations of the use of environmental tracers to infer groundwater age. Ground Water 53(Suppl 1):56-70. doi:10.1111/gwat.12237

McMahon PB, Chapelle FH, Jaguckl ML (1992) Atrazine mineralization potential of alluvial-aquifer sediments under aerobic conditions. Environ Sci Technol 26:1556-1559

Mills MS, Thurman EM (1994) Preferential dealkylation reactions of s-triazine herbicides in the unsaturated zone. Environ Sci Technol 28:600-605. doi:10.1021/es00053a011

Pedersen PG (2000) Pesticides degradability in groundwater: importance of redox conditions. PhD thesis. Technical University of Denmark. $79 \mathrm{p}$ 
Rodríguez CJ, Harkin JM (1997) Degradation of atrazine in subsoils, and groundwater mixed with aquifer sediments. Bull Environ Contam Toxicol 59:728-735

Sannino F, Filazzola MT, Violante A, Gianfreda L (1999) Adsorptiondesorption of simazine on montmorillonite coated by hydroxy aluminum species. Environ Sci Technol 33:4221-4225

Sassine L (2014) Occurrence of pesticides and emerging contaminants in an alluvial aquifer. Linking to groundwater origin and residence time. Case study of the Vistrenque aquifer. AixMarseille University, PhD dissertation, 127 p. (In French)

Sassine L, Khaska M, Ressouche S, et al. (2015) Coupling geochemical tracers and pesticides to determine recharge origins of a shallow alluvial aquifer: case study of the Vistrenque hydrogeosystem (SE France). Appl Geochem 56:11-22

Schlosser P, Stute M, Dörr H, et al. (1988) Tritium/3He dating of shallow groundwater. Earth Planet Sci Lett 89:353-362

Schlosser P, Stute M, Sonntag C, Münnich KO (1989) Tritiogenic 3He in shallow groundwater. Earth Planet Sci Lett 94:245-256

SMNVC (2002) Suivi des pesticides. Interprétations des résultats et premières conclusions. (In French)

Stackelberg PE, Barbash JE, Gilliom RJ, et al. (2012) Regression models for estimating concentrations of atrazine plus deethylatrazine in shallow groundwater in agricultural areas of the United States. J Environ Qual 41:479-494. doi: $10.2134 /$ jeq2011.0200

Steele GV, Johnson HM, Sandstrom MW, et al. (2008) Occurrence and fate of pesticides in four contrasting agricultural settings in the United States. J Environ Qual 37:1116-1132. doi:10.2134 /jeq2007.0166

Suckow A (2014) The age of groundwater-definitions, models and why we do not need this term. Appl Geochem. doi:10.1016/j. apgeochem.2014.04.016

Tappe W, Groeneweg J, Jantsch B (2002) Diffuse atrazine pollution in German aquifers. Biodegradation 13:3-10

Tesoriero AJ, Saad DA, Burow KR, et al. (2007) Linking ground-water age and chemistry data along flow paths: implications for trends and transformations of nitrate and pesticides. J Contam Hydrol 94:139- 155. doi:10.1016/j.jconhyd.2007.05.007

Visser A, Fourré E, Barbecot F, et al. (2014) Intercomparison of tritium and noble gases analyses, $3 \mathrm{H} / 3 \mathrm{He}$ ages and derived parameters excess air and recharge temperature. Appl Geochem. doi:10.1016/j. apgeochem.2014.03.005

Vonberg D, Vanderborght J, Cremer N, et al. (2014) 20 years of longterm atrazine monitoring in a shallow aquifer in western Germany. Water Res 50:294-306. doi:10.1016/j.watres.2013.10.032 